\title{
Behavior of Layers under Different Light Sources
}

\section{-Author(s)}

\section{Tavares $\mathrm{BO}^{\circ}$ \\ Pereira DF' \\ Bueno LGF"}

Silva GF"

São Paulo State University "Júlio de
Mesquita Filho", Tupã, São Paulo "Júlio de

Mesquita Filho", Dracena, São Paulo

\section{ABSTRACT}

Light is an important factor in the management of laying poultry. The ideal lamp spectrum that provides the best welfare conditions still needs to be determined. Wavelength and light intensity influence poultry behavior and their welfare. This study evaluated the influence of four lamps types with different light spectra on the behavior of seventy 52-week laying hens. Incandescent, fluorescent, and sodium and mercury vapor lamps were set in a different poultry house each and supplied similar light intensities. Layer behavior was video-recorded three times weekly using video cameras installed on the ceiling. The effects of different wavelengths emitted by the light sources on layer behavior were evaluated by the Kruskal-Wallis median test. Results indicated that incandescent and sodium vapor lamps increased the occurrence of nesting, and of active behaviors, such as floor-scratching and pecking.

\section{INTRODUCTION}

Several studies have demonstrated that light is an important factor for the management of poultry health and behavior. In fact, it may affect them through interactions between physiological and behavioral responses.

Poultry physiological characteristics should be taken into account since natural or artificial light stimulus influences their motor, reproductive, and growth activities. Studies have shown that the greatest difficulty lies in separating the effect of the wavelength from light intensity on these parameters (Deep et al. 2012; Gunnarssona et al., 2008; Kristensen et al., 2007)

Poultry are more sensitive to environmental luminosity, i.e, wavelengths, than humans (Vercellino et al., 2013).

Since most broilers and laying hens are commercially reared in environments with artificial light, adequate lighting management on commercial farms is essential for optimizing bird welfare and production efficiency (Silva et al., 2013; Pereira et al., 2015). Because light influences the behavior of reproducing poultry and commercial parameters, visual stimuli are a powerful management tool in the hands of the producer. The effects of each light source on poultry behavior and performance may be employed to improve rearing conditions, and consequently farm economic results.

Aiming at testing the hypothesis that lamps with different light spectra affect layer behavior, this study evaluated the effects of the use of different light sources on the behavior of layers. 


\section{MATERIALS AND METHODS}

The experiment was performed at UNESP Experimental Campus in Tupã, in the western region of the state of São Paulo, Brazil. According to Köppen's classification, climate is tropical, with a dry season during winter and mean annual temperature above $22^{\circ} \mathrm{C}$.

Four reduced-scale (4.5 $\mathrm{m}^{2}$ internal area) poultry houses were built on a flat plot in east-west direction, according to the recommendations of Nääs (1989) and Tinôco (2001). East and west sides were closed with bricks, and north and south sides, with wire mesh. The floor was made of concrete and was covered with new wood-shavings litter. The roof was made of fibercement tiles. Each house was divided in two $2.25-\mathrm{m}^{2}$ areas by wire mesh, but only one of the areas was used during the trial.

Black-out curtains were used on the open sides and lowered at 09:00 $\mathrm{h}$ and raised at 18:30 $\mathrm{h}$ daily to provide natural ventilation and a mixed lighting system (natural and artificial lighting).

Seventy 52-week-old Dekalb laying hens acquired from a commercial layer farm were distributed into four light source treatments (17 or 18 hens per pen). Lamps were switched on at 05:00 h and switched off at 21:00 h, comprising a 16-hour photoperiod. Lighting system control was automatic by time relays placed in the electric circuits of each house.

All birds were a same diet, which was provided ad libitum, according to feeding management of the farm

a)

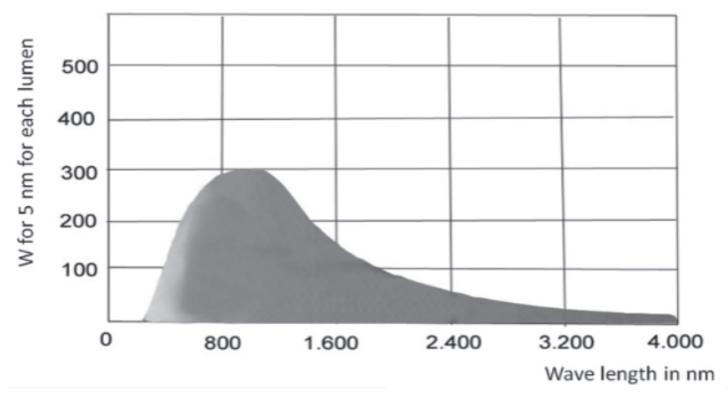

b)

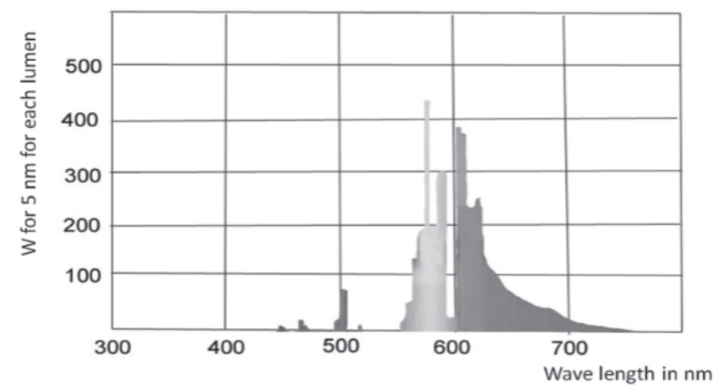

of origin. Water was provided by four nipple drinkers per pen.

Four types of lamps (incandescent, fluorescent, and sodium and mercury vapor lamps) were employed in the experiment. Figure 1 shows the spectrum curves of the lamps.

The lamp power and number in each house were calculated with the objective of providing the same light intensity in all houses, thereby isolating the influence of the light spectrum. The average lumen method was used to calculate the number of lamps that would produce the same light intensity in the four houses. Light flow was calculated according to Equation 1.

$$
\Phi=\frac{E * S}{\mu * d}
$$

where $\phi=$ light flow in lumen; $\mathrm{E}=$ light intensity in lux; $\mathrm{S}=$ house area in $\mathrm{m}^{2} ; \mu=$ coefficient of usage; $d=$ coefficient of depreciation.

Based on total light flow, the number of lamps required was determined using Equation 2.

$$
n=\frac{\phi}{\emptyset}
$$

where $\mathrm{n}=$ number of lamps; $\phi=$ light flow in lumen; $\varnothing=$ light flow of each lamp.

c)

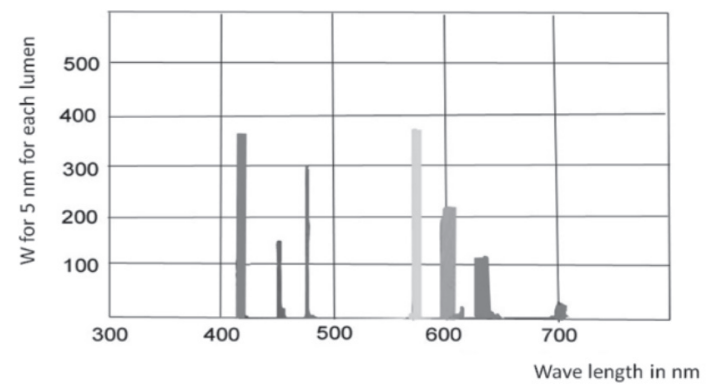

d)

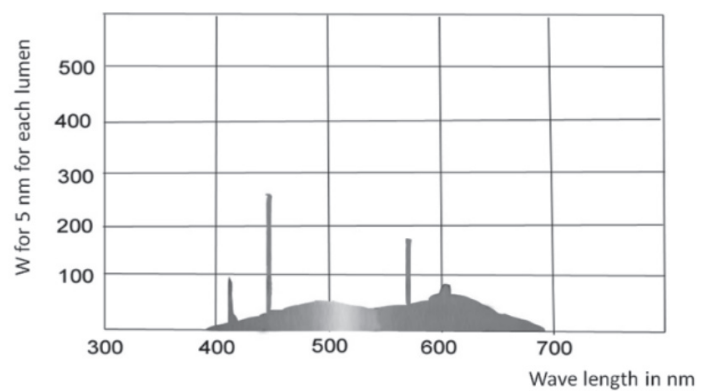

Figure 1. Spectrum distribution of energy from a) incandescent lamp; b) mercury vapor lamp; c) sodium vapor lamp; d) fluorescent lamp. 
Considering the reduced area of the experimental houses, a mercury vapor lamp was installed, because it is the lamp that emits the highest light flow, and therefore, determined the light intensity required in the other houses. Light intensity of the mercury vapor lamp was measured as approximately 265 lux. The expected light intensity was calculated for all houses and the actual light intensity was measured using a digital Icel LD-510 Lux Meter. Table 1 provides a number of lamps and their respective powers.

Table 1 - Number of lamps in each shed; light level calculated and measured with LD-510.

\begin{tabular}{llcc}
\hline Light source & Number of lamps & $\begin{array}{c}\text { Calculated } \\
\text { luminance (lux) }\end{array}$ & $\begin{array}{c}\text { Mean } \\
\text { luminance (lux) }\end{array}$ \\
\hline Mercury vapor & $1 \times 125 \mathrm{~W}$ & 265 & 243 \\
Sodium vapor & $1 \times 75 \mathrm{~W}$ & 240 & 225 \\
Incandescent & $4 \times 100 \mathrm{~W}+1 \times 40 \mathrm{~W}$ & 246 & 277 \\
Fluorescent & $4 \times 20 \mathrm{~W}+1 \times 15 \mathrm{~W}$ & 249 & 247 \\
\hline
\end{tabular}

The behaviors expressed by the bird were recorded using video cameras placed on the ceiling (one per house) in order to prevent any influence of humans during recordings. Video footages were managed by a GeoVision 800 and its respective software in a computer located at the Environmental Comfort Lab of UNESP campus Tupã.

The occurrence (number of times any bird in each group expressed a specific behavior) and duration (in seconds) of each behavior were quantified. Behaviors were video-recorded for 15 minutes on the first three days of each week during the morning (09:00-09:15 h) and the evening (19:15-19:30 h). During these periods, the side curtains were closed, and therefore, the birds were under the influence of the lamps. Behavioral data were recorded using a random daily footage, i.e., out of the daily footages, one 15-min footage was used. Table 2 describes the behaviors analyzed in current study.
The numerical datasets of each evaluated parameter were submitted to the normality test of KolmogorovSmirnov, and medians were compared by the nonparametric test of Kruskal-Wallis, using Minitab $16^{\circledR}$ statistical software. All tests were performed at 5\% significance level.

\section{RESULTS AND DISCUSSION}

Considering that all other environmental variables (external temperature, feeding, water availability, poultry house characteristics, and light level) were equal in all treatments, the behavioral difference among treatments indicate response to the light source.

The occurrence of natural behaviors can be used as measure of welfare in animals. Perching (Nicol et al., 2009), and floor-scratching and pecking are some of the natural behaviors of poultry reported in literature.

The results of occurrence and duration of the evaluated behaviors are shown in Tables 4 and 5, respectively.

The occurrence floor-scratching was higher in the layers maintained in the house with the sodium vapor lamp compared with those under the other evaluated lamp sources $(p<0.05 T h e$ occurrence of resting on the nest was significantly higher in layers under the incandescent light source compared with those maintained under sodium and mercury vapor lamps.

According to Becker (2002), animal welfare is influenced by physiological and behavioral parameters. Deep et al. (2012) evaluated the impact of light intensity on the behavior and daily rhythm of broilers submitted to light intensities of 1, 10, 20 and $40 \mathrm{Ix}$, as well as estimated blood melatonin levels three times of day. The authors found that light intensity did not affect melatonin levels or behavioral diurnal rhythms, but birds exposed to a light intensity of 1 lux rested more and preened less, potentially indicating a

Table 2 - Ethogram of reported behavior

\begin{tabular}{|c|c|c|}
\hline Behavior & Description & Measurement \\
\hline Feather preening & The birds preens its feathers with the beak and stimulates the uropygial gland. & Duration occurrence \\
\hline Wing flapping & A movement by which the bird flaps both wings. & Occurrence \\
\hline Drinking & The bird positions itself in front of the trough and drinks water. & Duration occurrence \\
\hline Pecking & A bird aggressively pecks the body of another bird. & Occurrence \\
\hline Scratching & The bird scratches the ground with one foot or both feet. & Duration occurrence \\
\hline Eating & The bird positions itself in front of the trough and eats. & Duration occurrence \\
\hline Lying & Birds lies down on the litter. & Duration occurrence \\
\hline Sitting on the nest & The birds climbs to the nest and rests. & Duration occurrence \\
\hline Perching & The birds climbs the perch and rests. & Duration occurrence \\
\hline Leg stretching & The bird stretches a wing or a foot of the same body hemisphere. & Occurrence \\
\hline Pursuit & The birds pursuits another bird. & Occurrence \\
\hline
\end{tabular}


Table 3 - Median occurrence of the behaviors of layers exposed to four different light sources.

\begin{tabular}{lcccc}
\hline & & \multicolumn{3}{c}{ Treatments } \\
\cline { 2 - 5 } Behavior & Incandescent & Fluorescent & Sodium vapor & Mercury vapor \\
\hline Wing flapping & 4.0 & 3.5 & 3.0 & 3.0 \\
Preening & 4.0 & 4.0 & 3.0 & 4.0 \\
Drinking & 8.0 & 11.5 & 9.0 & 10.0 \\
Pecking & 1.0 & 1.5 & 2.0 & 1.0 \\
Floor-scratching & $1.0^{\mathrm{b}}$ & $1.0^{\mathrm{b}}$ & $2.5^{\mathrm{a}}$ & $2.0^{\mathrm{b}}$ \\
Eating & 13.0 & 11.5 & 13.0 & 14.5 \\
Resting & 2.0 & 1.0 & 1.0 & 1.0 \\
Sitting on the nest & $5.0^{\mathrm{a}}$ & $4.5^{\mathrm{ab}}$ & $3.0^{\mathrm{b}}$ & $3.5^{\mathrm{b}}$ \\
Perching & 6.0 & 7.0 & 6.0 & 6.0 \\
Leg stretching & 1.0 & 1.0 & 1.0 & 1.0 \\
Pursuit & 1.0 & 2.0 & 1.0 & 1.0 \\
\hline
\end{tabular}

Figure followed by different superscripts indicate significant difference $(p<0.05)$ by Kruskal-Wallis non-parametric median comparison test.

reduced welfare state. Prayitno et al. (1997) observed that broilers exposed to bright red light considerably increased walking, feeding and stretching, which are active behaviors, and consequently presented lower incidence of gait abnormalities, and therefore, better welfare compared with broilers reared under low light intensity. night illumination contrast than that typically applied in commercial broiler production.

Blatchford et al. (2009), in a study on the effect of light intensity on broiler behavior and health, also found that birds reared under low light intensity were less active during the day and a more uniform behavioral rhythm during the day than those maintained under

Table 4 - Median duration (minutes) of the behaviors of layers exposed to four different light sources.

\begin{tabular}{|c|c|c|c|c|}
\hline \multirow{2}{*}{ Behavior } & \multicolumn{4}{|c|}{ Treatments (light source) } \\
\hline & Incandescent (1) & Fluorescent (2) & Sodium vapor (3) & Mercury vapor (4) \\
\hline Preening & 270.0 & 324.5 & 288.0 & 294.0 \\
\hline Drinking & 150.0 & 174.5 & 143.0 & 138.0 \\
\hline Floor-scratching & 101.0 & 73.0 & 134.5 & 70.0 \\
\hline Eating & 208.5 & 292.0 & 263.0 & 170.0 \\
\hline Resting & 170.0 & 158.5 & 352.0 & 120.0 \\
\hline Resting on the nest & 175.0 & 248.5 & 174.0 & 222.5 \\
\hline Perching & 340.0 & 279.0 & 395.0 & 251.0 \\
\hline
\end{tabular}

Different letters between treatments indicate significant difference $(p<0.05)$ by Kruskal-Wallis non-parametric median comparison test.

Vercellino et al (2013) evaluated the influence of side-curtain color on the behavior of broiler chickens raised in a dark-out house and observed that birds reared in the house with yellow curtains, which provide higher intensity, expressed a greater number of behaviors linked to welfare; however, better uniformity and productivity were obtained when broilers were reared in the house with blue curtains.

Alvino et al. (2009) evaluated the behavior of broilers subjected to 5, 50, or 200 lux, and verified that broilers exposed to the lowest light intensity ( 5 lux) presented a more even distribution of behaviors over the photoperiod compared with those exposed to 50 and 200 lux. Those authors argue, in the light of these results, that the potential welfare benefits of rearing broilers in environments with greater day- higher light intensity (50 and 200 lux). In addition, despite the lack of differences in gait score, the broilers reared under high light intensity (200 lux), presented more hock and footpad lesions.

No difference in the occurrence of other evaluated behaviors were detected among treatments (Table 3 ). Moreover, different light sources did not affect the duration of behaviors of laying hens (Table 4).

\section{CONCLUSION}

Light sources influenced the behavior of layers. The lamp sources emitting longer waves caused layers to be more active. This result suggests that adequate lighting management may be beneficial to poultry welfare. 


\section{ACKNOWLEDGEMENTS}

The authors would like to thank Granja Recanto Alegre in Tupã SP Brazil for providing the hens and feed. Thanks are also due to CNPq for Scientific Initiation Scholarship and to FAPESP (Process 2010/19064-0) for Research Funding.

\section{REFERENCES}

Alvino GM, Archer GS, Mench JA. Behavioural time budgets of broiler chickens reared in varying light intensities. Applied Animal Behaviour Science 2009;118:54-61

Barbosa Filho JAD, Silva IJO, Silva MAN, Silva CJM. Avaliação dos comportamentos de poedeiras utilizando sequência de imagens. The laying behavior assessment using sequence of images. Engenharia Agrícola 2007;27:93-99.

Becker BG. Comportamento das aves e sua aplicação prática. Behavior of birds and their practical application. Anais da Conferência Apinco de Ciência e Tecnologia Avícolas; 2002; Campinas, São Paulo. Brasil. p. 81-90

Blatchford RA, Klasing KC, Shivaprasad HL, Wakenell PS, Archer GS, Mench JA. The effect of light intensity on the behavior, eye and leg health, and immune function of broiler chickens. Poultry Science 2009;88:20-28

Deep A, Schwean-Lardner K, Crowe TG, Fancher BI, Classen HL. Effect of light intensity on broiler behaviour and diurnal rhythms. Applied Animal Behaviour Science 2012;136:50-56.
Gunnarssona S, Heikkiläb M, Hultgrena J, Valros A. A note on light preference in layer pullets reared in incandescent or natural light. Applied Animal Behaviour Science 2008;112(3-4):395-399.

Kristensen HH, Prescottc NB, Perryd GC, Ladewiga J, Ersbøllb AK, Overvada KC, Wathes CM. The behaviour of broiler chickens in different light sources and illuminances. Applied Animal Behaviour Science 2007:103:75-89.

Nääs IA. Princípios de conforto térmico na produção animal. São Paulo: Ícone; 1989.

Nicol CJ, Caplen G, Edgar J e Browne WJ. Associations between welfare indicators and environmental choice in laying hens. Applied Animal Behaviour Science 2009;78:413-424.

Pereira DF, Batista ED, Sanches FT, Gabriel Filho LRA, Bueno LGF. Diferenças comportamentais de poedeiras em diferentes ambientes térmicos. Energia na Agricultura 2015;30:32-39.

Prayitno DS1, Phillips CJ, Stokes DK. The effects of color and intensity of light on behavior and leg disorders in broiler chickens. Poultry Science 1997; 12:1674-1681.

Silva GF, Pereira DF, Bueno LGF, Santos TS, Tavares BO. Performance of laying hens and economic viability of different climatization systems. Italian Journal of Animal Science 2013;12:286-294.

Vercellino RA, Moura DJ, Nääs IA, Maia AA, Medeiros BBL, Salgado DDA, Carvalho TRM. The influence of side-curtain color on broiler chick behavior. Brazilian Journal of Poultry Science 2013;15:169-286. 
